\title{
La Satisfacción Laboral y sus Implicaciones en la empresa de hoy
}

\author{
Autor : Jorge Alberto Zelaya Cobos \\ Catedratico de la Universidad Jose Simeon Cañas \\ Licenciado en Administracion de Empresas
}

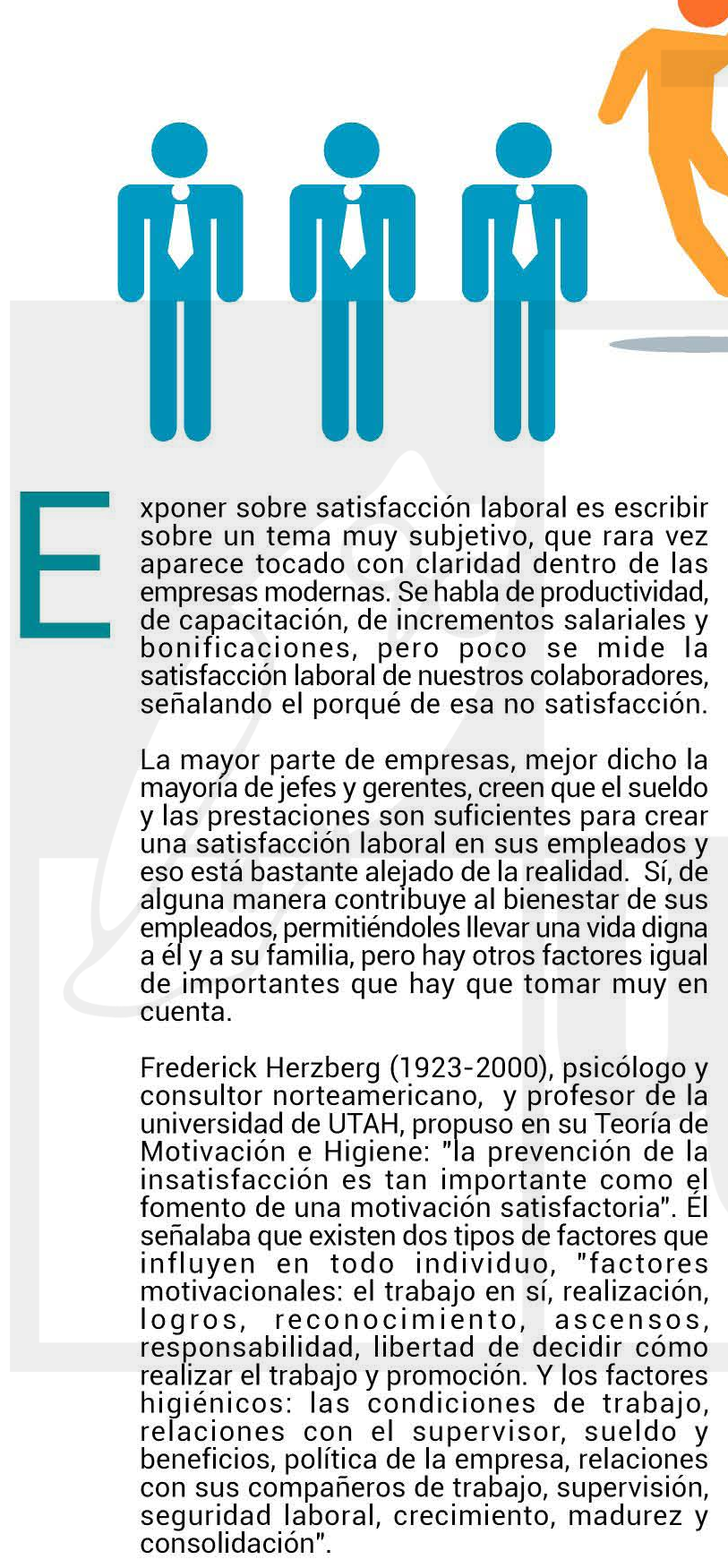

Asimismo, señala como efectos deseables:

1. Aumento de motivación
2. Aumento de la productividad

3. Reducción del ausentismo y de la rotación de personal.

Como efectos indeseables, señala:

1. Aumento de la ansiedad

2. Sentimientos de explotación

3. Reducción de las relaciones interpersonales

Abordando este tema, desde una metodología bibliográfica y de mis observaciones a través de más de 20 años de trabajar en diferentes empresas nacionales y organismos internacionales, quisiera acotar sobre un planteamiento que tiene una directa relación con el tema principal y es el Síndrome de Estocolmo Laboral.

En 1973, en la ciudad de Estocolmo, Suecia, durante un asalto bancario en el que las personas que se encontraban adentro terminaron siendo rehenes de los ladrones, se pudo apreciar cómo una de las víctimaș se besaba con uno de los delincuentes. Éste suceso fue captado en una fotografía realizada por un periodista. Esta peculiar y nada común situación, originó que se asociara el nombre de "Estocolmo" a un síndrome o comportamiento humano, en el cual, la víctima se identifica con el victimario, gracias a la actitud protectora del mismo.

Según expertos, los casos se presentan solo cuando la persona secuestrada cree que el victimario asume el "rol" de algún integrante de la familia, es decir, padre, madre, hermano, entre otros. Esto surge cuando el secuestrador, pese a que mantiene en cautiverio a la persona en cuestión, le brinda protección a fin que sufra lo menos posible. 


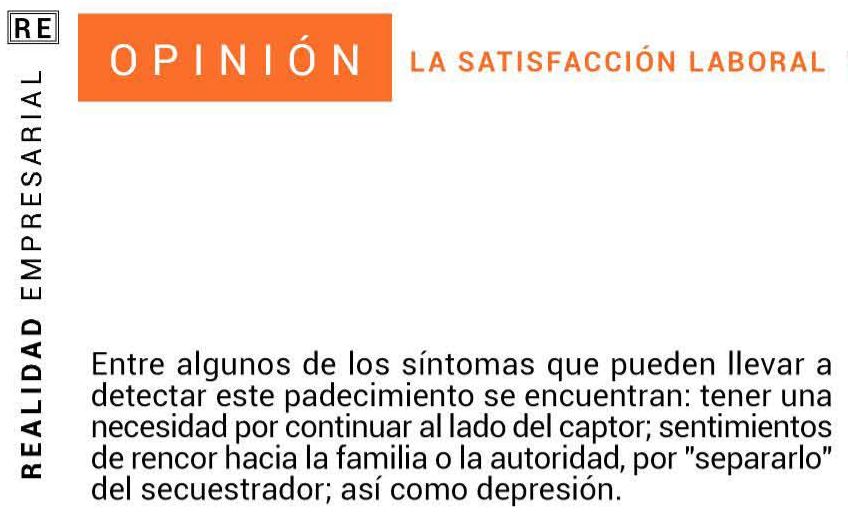

Existe una variante de este trastorno psicológico, que es el Síndrome de Estocolmo Laboral. Este se presenta cuando la persona se aferra a permanecer en algún empleo en donde el ambiente es hostil. A diferencia del síndrome en su forma clásica, en esta situación la víctima no es forzada a estar en algún lugar, sino que lo hace por propia voluntad.

Por el contrario, ha ingresado por su entera voluntad y se mantiene atada a ese escenario, ya sea porque es incapaz de concebir su vida sin las presiones, maltratos y limitaciones que encuentra en el empleo, o bien porque es absorbida por una cantidad, a veces inverosímil, de razones que le impiden deshacerse del mismo.

Esto quiere decir que existen colaboradores que se han identificado emocionalmente con algunas empresas que ofrecen condiciones inadecuadas de trabajo, maltrato psicológico (e incluso físico) y situaciones de estrés, producto de una presión innecesaria que, estando prácticamente en un cautiverio voluntario, prefieren mantener ese estado de angustia o presión que abandonar el escenario que la causa.

¿Por qué estas personas, a pesar del maltrato recibido, se aferran a estas empresas?

Según estudios practicados a un gran número de personas, quienes son sometidas a maltratos laborales, se consiguieron razones que estas alegan para mantenerse sufriendo.

\section{Estas justificaciones son las siguientes:}

- Conocen al jefe, saben cómo manejar la situación

- Hay pocas posibilidades de encontrar otro empleo en la actualidad

- Con el tiempo uno se acostumbra

- Es el estilo de la empresa

- No hay otras opciones

- Mejor esto que nada

- Me gusta lo que hago, no la empresa.
El Síndrome de Estocolmo Laboral es un fenómeno más común de lo que parece. Se observa en personas de todo tipo, nivel de educación, diferentes edades y niveles de maduración emocional. Por lo general, está asociado a baja autoestima, pero su característica más extraordinaria es la identificación con un estilo gerencial que pone en riesgo su salud física mental y emocional.

Actualmente en muchas empresas salvadoreñas, la alta dirección se preocupa por el mejoramiento de la conducta organizacional. El directivo, el profesional, el asistente y el operario, todos ellos trabajan con otras personas, lo cual influye en la calidad de vida que se desarrolla en los centros de trabajo. En este contexto, los gerentes (quienes toman las decisiones) y en especial el Gerente de Recursos Humanos, deben tratar de conocer las bases del comportamiento organizacional como medio para mejorar las relaciones entre las personas y la organización. Los gerentes tratarán de crear un ambiente en el que la gente se sienta motivada, trabaje más productivamente y sea más eficiente.

En este marco referencial, uno de los aspectos que más importancia tiene para el trabajador es lo que respecta a la satisfacción que le produce la labor que desempeña y los aspectos que rodean a su trabajo. Las teorías humanistas sostienen que el trabajador más satisfecho es aquel que satisface mayores necesidades psicológicas y sociales en su empleo $y$, por tanto, suele poner mayor dedicación a la tarea que realiza.

Una elevada satisfacción de los empleados en el trabajo es algo que deberá procurar la dirección de toda organización, porque tiende a relacionarse con los resultados positivos, con mayores índices de productividad, lo cual lleva al desarrollo empresarial. Debemos tener presente, lo que propone Abraham Maslow (1943) en su pirámide de necesidades humanas.

Si se detectara en una empresa el acoso laboral, de parte de quien sea, se deberá de poner fin a esta situación tomando las medidas oportunas para evitar este acto de crueldad mental, que podría llevar a consecuencias insospechables. 
A veces resulta difícil distinguir entre la motivación y la satisfacción laboral, debido a su estrecha relación. Lo mismo sucede entre la satisfacción con el trabajo y la moral del empleado. Muchos autores emplean ambos términos como si fueran sinónimos. La satisfacción en el empleo designa, básicamente, un conjunto de actitudes ante el trabajo. Podemos describirla como una disposición psicológica del sujeto hacia su trabajo y esto supone un grupo de actitudes y sentimientos. De ahí que la satisfacción o insatisfacción con el trabajo dependa de numerosos factores, como el ambiente físico donde trabaja, las buenas relaciones jefe-subalterno, el sentido de logro o realización que le procura el trabajo, la posibilidad de aplicar conocimientos y que su trabajo le permita desarrollar nuevos conocimientos y asumir retos. Hay otros factores que repercuten en la satisfacción y que no forman parte de la atmosfera laboral, pero que también influyen en el grado de satisfacción obtenido. Por ejemplo, la edad, la salud, la antigüedad, la estabilidad emocional, condición socio-económica, tiempo libre y actividades lúdicas, relaciones familiares y otros desahogos, afiliaciones sociales, etc.

En los adultos mayores, que pasan más de 10 años desempeñando el mismo cargo, se evidencia la insatisfacción laboral, por lo que es muy recomendable en las empresas, desarrollar una rotación de puestos (que permita conocer más sobre los objetivos de la gerencia o departamento al que se pertenece), pagar sueldos "realmente competitivos ", desarrollar programas motivacionales, brindar excelentes condiciones de trabajo, ofrecer prestaciones sociales (por encima de la ley que abarquen al grupo familiar), entre otras medidas, que se pueden implementar en el corto plazo .

Cada vez más, las empresas deben patrocinar y organizar eventos sociales y culturales, que permitan salir de la rutina a sus empleados. Lógicamente, todas las personas que trabajan y que pudieran experimentar algún grado de insatisfacción, deberán de desarrollar "otros intereses" fuera de la empresa, que les compensen el grado de frustración que una situación laboral pudiera ocasionar. Una vida rica en intereses lúdicos (leer, escribir, ir al teatro, ir al cine, paseos en familia o con amigos, coleccionar, realizar servicios sociales, hacer ejercicio, practicar algún deporte, etc.) permitirá una mayor salud mental, que nos ayudará a lidiar en mejor forma con la rutina.

Considero que la empresa de hoy debe realizar encuestas que le permitan medir el nivel de satisfacción laboral, por lo menos cada dos o tres años y con los resultados obtenidos tomar decisiones sabias, que permitan minimizar estos efectos para lo que, perfectamente podría contratarse los servicios de un consultor especialista en la materia.

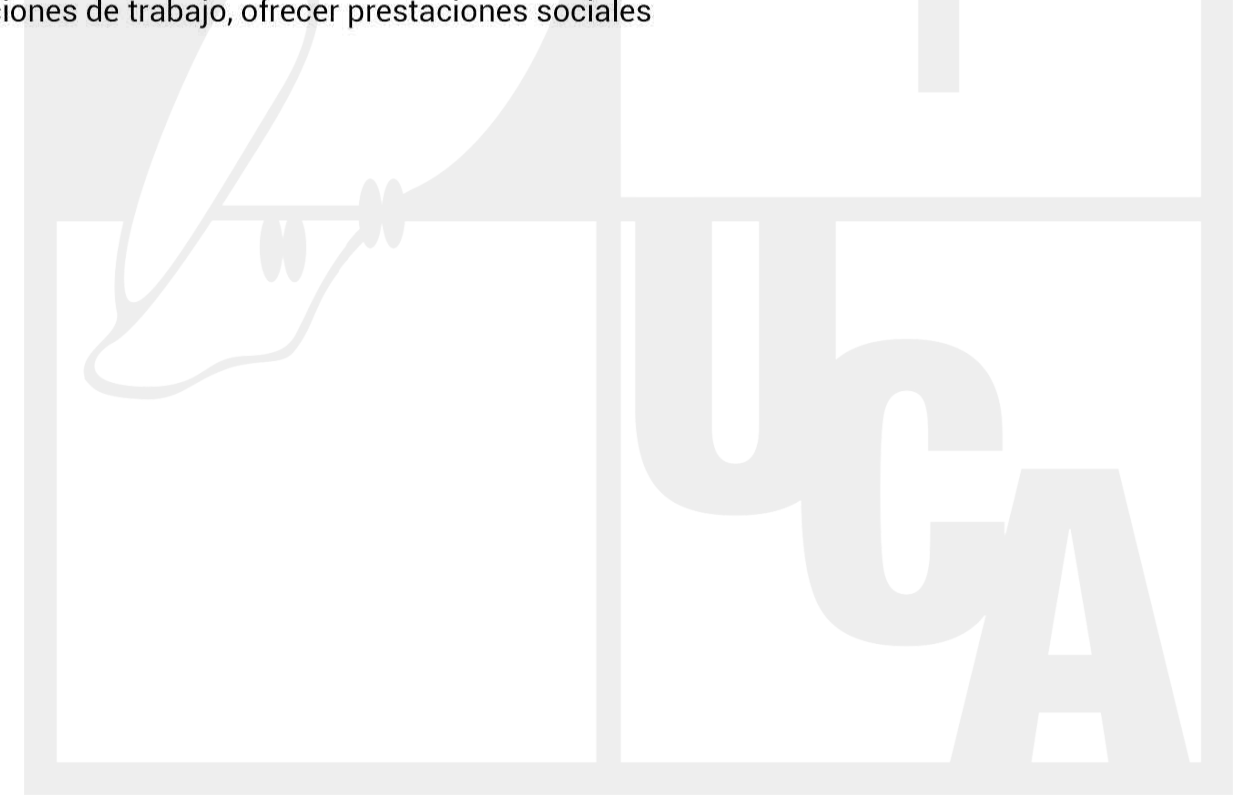

\section{Bibliografía}

Davis, Keith (1918)-. Newstrom, John W. (2003). Comportamiento humano en el trabajo. México: McGraw-Hill/Interamericana.

Schultz, Theodore W. (1985). Invirtiendo en la gente: la cualificación personal como motor económico. Barcelona: Ariel, 1985. 